\title{
Innovative statistical information system for tracking the quality of agricultural machinery production
}

\author{
Olesya Golubeva ${ }^{1, *}$, Georgiy Shemerey ${ }^{1}$, Viktor Mirnyy ${ }^{1}$, and Mikhail Chaava ${ }^{1}$ \\ ${ }^{1}$ Don State Technical University, 1, Gagarin Square, 344003, Rostov-on-Don, Russia
}

\begin{abstract}
This article highlights the functional aspect of developed software for statistical control of production quality and the possible areas of application of the developed software, in particular, manufacture of agricultural machinery at enterprises.
\end{abstract}

\section{Introduction}

The modern world is in a constant progress. Whatever area of knowledge you take, manual labor is being replaced by automatic everywhere, robotic production is replacing manual labor. Gradually, artificial intelligence is replacing management personnel. On the one hand, this speeds up the manufacturing process while minimizing production costs and improving the skills of personnel. On the other hand - brings up to a regular decrease in workplaces, which will soon become commonplace $[1,2]$.

This process - transition from the industrial to the post-industrial system is currently at the initial stage of its formation. This is evidenced by the fact that virtually no enterprise, no production can exist without being managed by a human.

Currently, there are information systems on the basis of which the process of managing enterprises for the manufacture of any product can take place. But these systems are far from perfect and require constant improvement [3].

In order to improve the quality of manufactured products, more flexible adjustment of the production process due to timely monitoring of defects in manufactured products at each stage of production, the use of modern technologies in the planning of production, for example, such as the Ishikawa chart, software was developed to solve many issues of the production process quality management due to automatic input processing using various quality tools.

\section{Materials and Methods}

The developed software is based on the functionality of automatic analysis and processing of input data from stationary computers of operators at each stage of the production process. Both identification with elimination of problem areas of production and the use of

\footnotetext{
*Corresponding author: 1354565@mail.ru
} 
new production methods of quality management with flexible adjustment of the manufacturing process and its timely adjustment can occur $[4,5]$.

This was made possible thanks to the implementation of statistical quality control methods: Shewhart X and R control charts, Pareto charts, control charts of the number and shares of discrepancies, control charts of the number of discrepancies, scatter charts in the developed software.

The production planning process has also become more flexible, by expanding the functionality of the created software with the ability to build Ishikawa charts.

Also one of the advantages of the developed software is the ability to implement it in a larger information system, under which the enterprise operates.

\section{Results of Research}

At the stage of writing the source code for the software, some types of productions, namely agricultural equipment, were analyzed [6]. Based on these data, methods for statistical control of the production process were selected for implementation in the developed information system:

- Pareto chart;

- Shewhart X and R control charts;

- scatter chart;

- control charts of the number and shares of discrepancies $\mathrm{P}$ and $\mathrm{nP}$;

- control charts of the number of discrepancies $\mathrm{C}$ and $\mathrm{U}$;

- Ishikawa chart.

It is these quality tools that are leaders in application when analyzing the production output data and adjusting of the entire manufacturing process [7].

The developed information system, intended for use on desktop computers [8], has extensive functionalities for analysis of statistical data, moreover, with the input of initial information by manual and automatic methods, the general view of which is shown in the figure 1 .

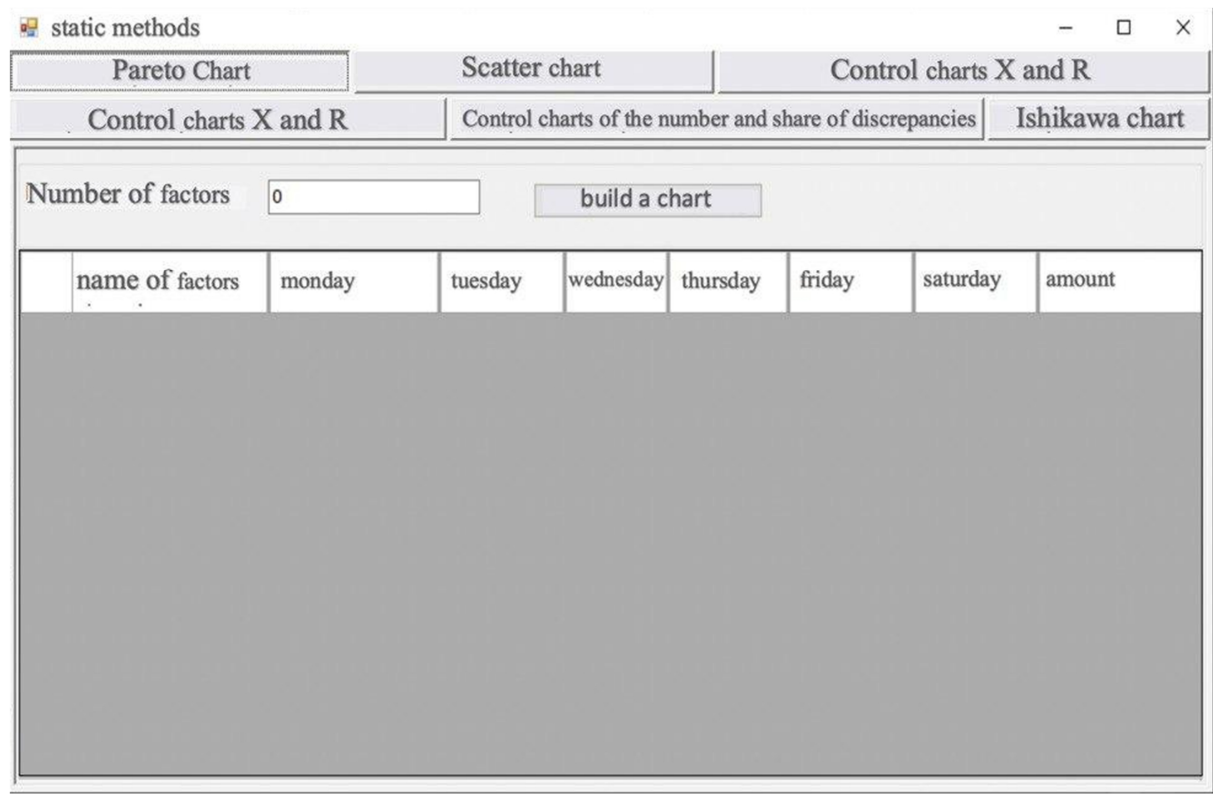

Fig. 1. Overview of the developed information system. 
Table 1. Overview of the developed information system.

\begin{tabular}{|c|}
\hline Static methods \\
\hline Pareto Chart \\
\hline Scatter chart \\
\hline Shewhart X and R control charts \\
\hline Control charts of the number of discrepancies \\
\hline Control charts of the number and share of discrepancies \\
\hline Ishikawa chart \\
\hline Number of factors \\
\hline Build a chart \\
\hline Factor name \\
\hline Monday \\
\hline Tuesday \\
\hline Wednesday \\
\hline Thursday \\
\hline Friday \\
\hline Saturday \\
\hline Sunday \\
\hline
\end{tabular}

At the initial stage of working with the software, it is possible to select the necessary quality tool, directly with an automatic or manual input method, which gives flexibility in the use of this software.

The first quality tool available is the Pareto chart.

A Pareto chart is a "series of columns whose height reflects the frequency or impact of a problem. The columns are arranged in descending order of height from left to right. This means that the categories represented by high bars on the left are relatively larger than on the right. The graph got its name from the Pareto principle, which postulates that 80 percent of problems stem from 20 percent of defects [9]. A general view of the operation screen of this quality tool in the developed software tool is shown in the figure 2 .

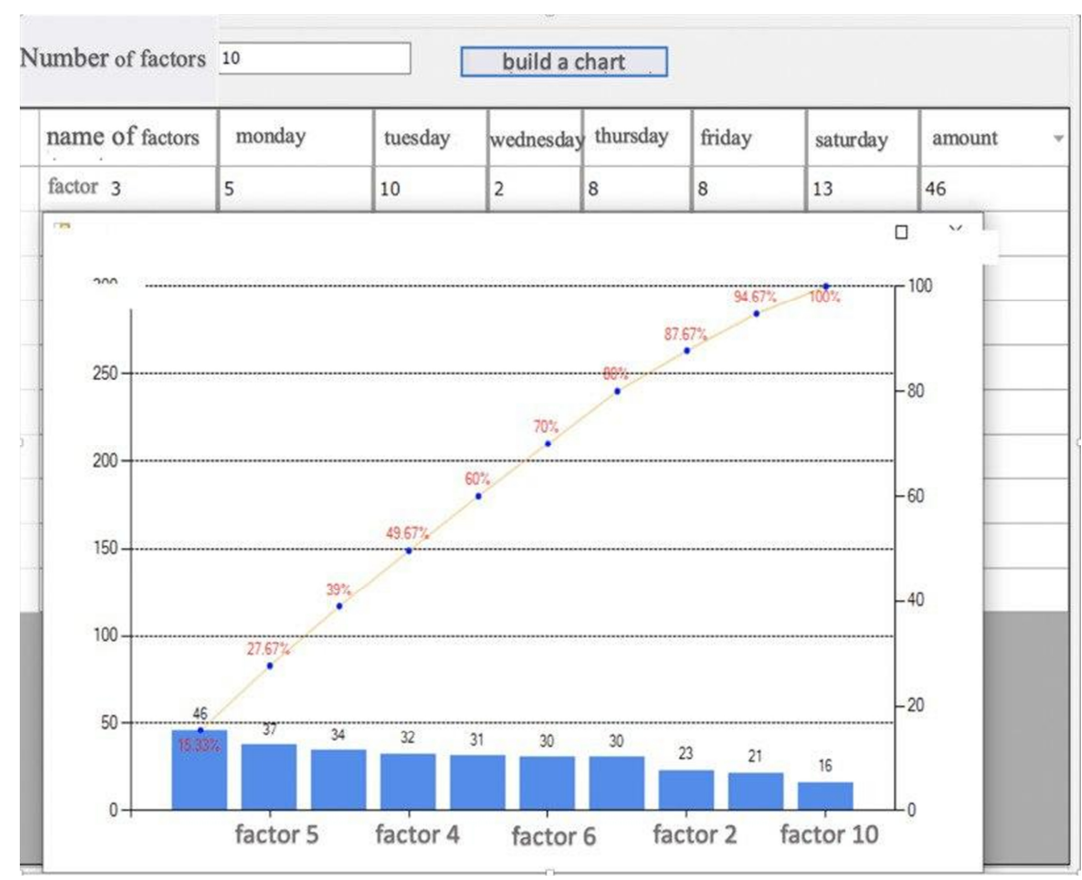

Fig. 2. Overview of the quality tool "Pareto Chart" in the developed software. 
Table 2. Overview of the quality tool "Pareto Chart" in the developed software.

\begin{tabular}{|c|}
\hline Pareto Chart \\
\hline Scatter chart \\
\hline Shewhart X and R control charts \\
\hline Control charts of the number of discrepancies \\
\hline Control charts of the number and share of discrepancies \\
\hline Ishikawa chart \\
\hline Number of factors \\
\hline Build a chart \\
\hline Factor name \\
\hline Monday \\
\hline Tuesday \\
\hline Wednesday \\
\hline Thursday \\
\hline Friday \\
\hline Saturday \\
\hline Amount \\
\hline Factor 3 \\
\hline Factor 4 \\
\hline Factor 5 \\
\hline Factor 6 \\
\hline Factor 2 \\
\hline Factor 10 \\
\hline
\end{tabular}

Another quality tool available for use in the developed information system is one of the most popular tool for statistical analysis of the production process - "Control charts X and R".

$\mathrm{X}$ and $\mathrm{R}$ control charts are a widely used control chart for variable data that allows you to explore process stability in many branches of knowledge. They are used to monitor the process performance of continuous data and the data that must be collected in subgroups at set time periods. In fact, these are two graphs for monitoring the average value of a process and the process change over time. These combined charts help identify process stability, as well as detect the presence of specific causes of change [10].

Overview of the quality tool "Control charts X and R" in the developed software tool is presented in the figure 3. 


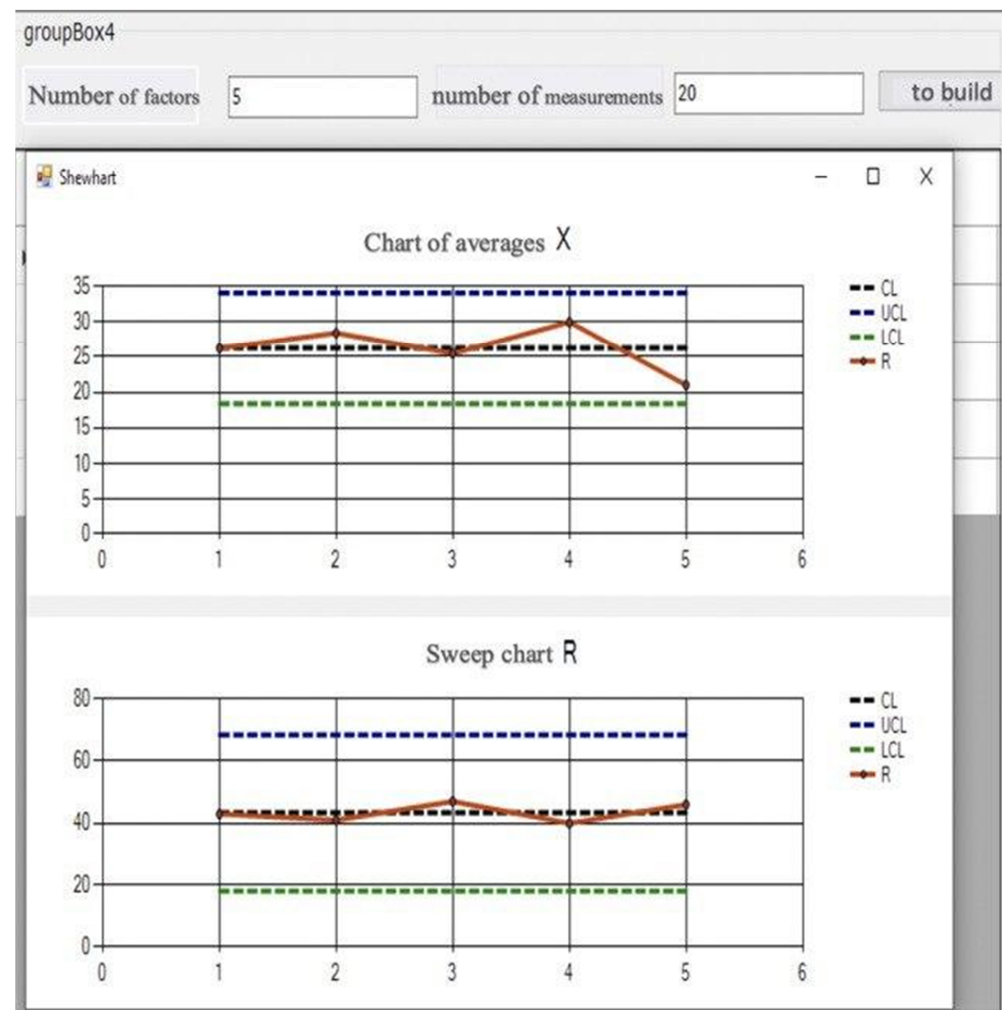

Fig. 3. Overview of the quality tool "Control charts $X$ and R" in the developed software tool.

Table 3. Overview of the quality tool "Control charts $\mathrm{X}$ and R" in the developed software tool.

\begin{tabular}{|c|}
\hline Pareto Chart \\
\hline Scatter chart \\
\hline Shewhart X and R control charts \\
\hline $\begin{array}{c}\text { Control charts of the number of } \\
\text { discrepancies }\end{array}$ \\
\hline $\begin{array}{c}\text { Control charts of the number and share } \\
\text { of discrepancies }\end{array}$ \\
\hline Ishikawa chart \\
\hline Subgroups number \\
\hline Measurement number \\
\hline Build a chart \\
\hline Average X Chart \\
\hline R Range Chart \\
\hline
\end{tabular}

The next available quality tool for working in the software is the "Scatter Chart", which is very often used for statistical analysis of the production process.

A scatter chart, or point-by-point chart, is a tool for describing changes in a dependent variable with respect to any changes in an independent variable. After determining the correlation between such variables, it is possible to predict the behavior of the dependent variable based on the independent indicator. This chart is useful when one variable is measurable and the other is not [11]. The overview of working with the "Scatter Chart" in the developed software is shown in the figure 4. 


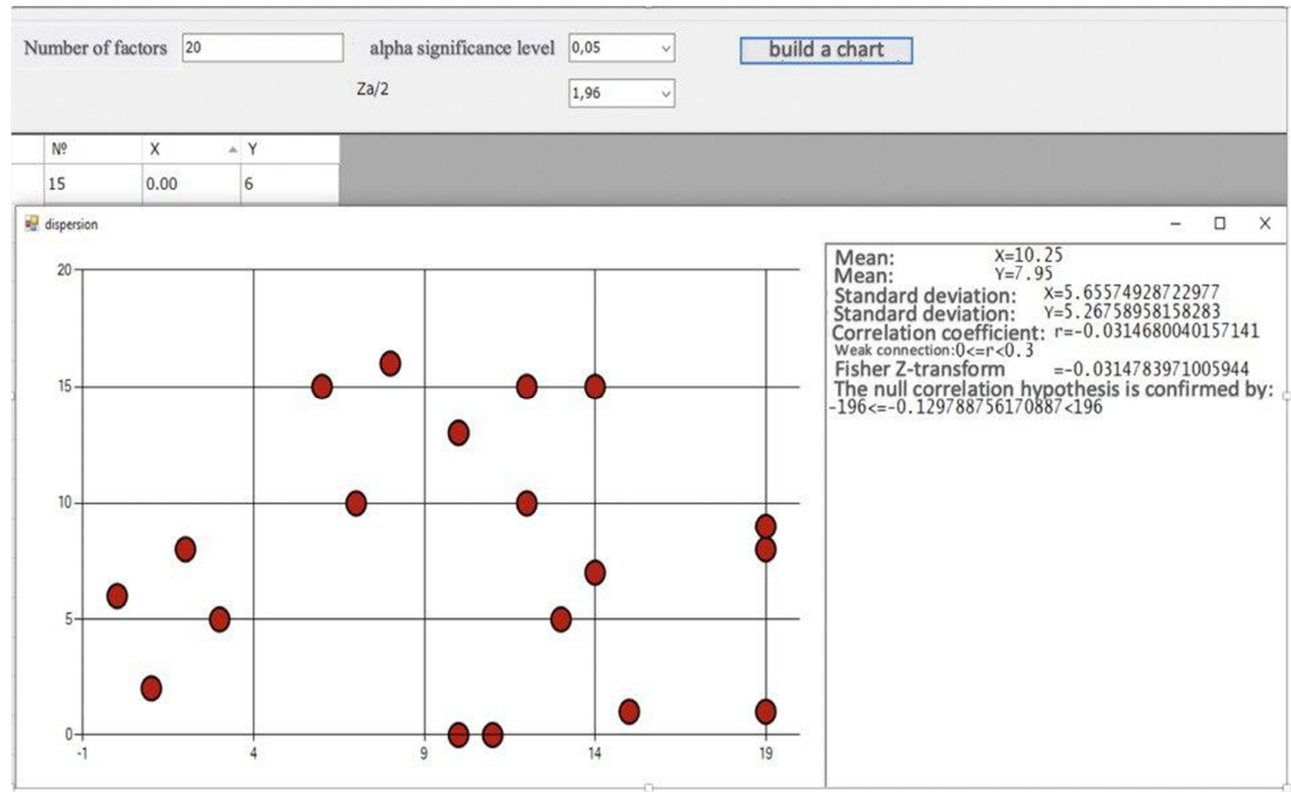

Fig. 4. Overview of the "Scatter Chart" quality tool in the developed software.

Table 4. Overview of the "Scatter Chart" quality tool in the developed software.

\begin{tabular}{|c|}
\hline Pareto Chart \\
\hline Scatter chart \\
\hline Shewhart X and R control charts \\
\hline Control charts of the number of discrepancies \\
\hline Control charts of the number and share of discrepancies \\
\hline Ishikawa chart \\
\hline Number of factors \\
\hline Alpha significance level \\
\hline Build a chart \\
\hline Average value $\mathrm{X}$ \\
\hline Average value $\mathrm{Y}$ \\
\hline Mean square deviation $\mathrm{X}$ \\
\hline Mean square deviation $\mathrm{Y}$ \\
\hline Correlation factor $\mathrm{r}$ \\
\hline Weak bonding \\
\hline Fisher Z-transformation \\
\hline Zero correlation hypothesis confirmed \\
\hline
\end{tabular}

The next quality tool presented in the developed software is "Control charts $\mathrm{P}$ and $\mathrm{nP}$ of the number and share of discrepancies".

Type $\mathrm{p}$ control charts are used to analyze discrete attribute data, since such data appears when classifying or grouping each measured instance. For example, when tracking faulty and serviceable components during production.

When each data point plotted on a control map is based on the same sample size, a special version of the $p$-chart can be used. The nP chart follows the same principle as the $p$ diagram, but actually displays the number of instances in the category over time, rather than the proportion in the category. The name " $\mathrm{nP}$ " comes from the convention of using " $\mathrm{n}$ " to indicate sample size. Multiplying the sample size by the proportion ( $\mathrm{n}$ p), we get the actual number in the category. 
The overview of these quality tools in the developed information system is presented in Figure 5 .

The null correlation hypothesis is confirmed by:

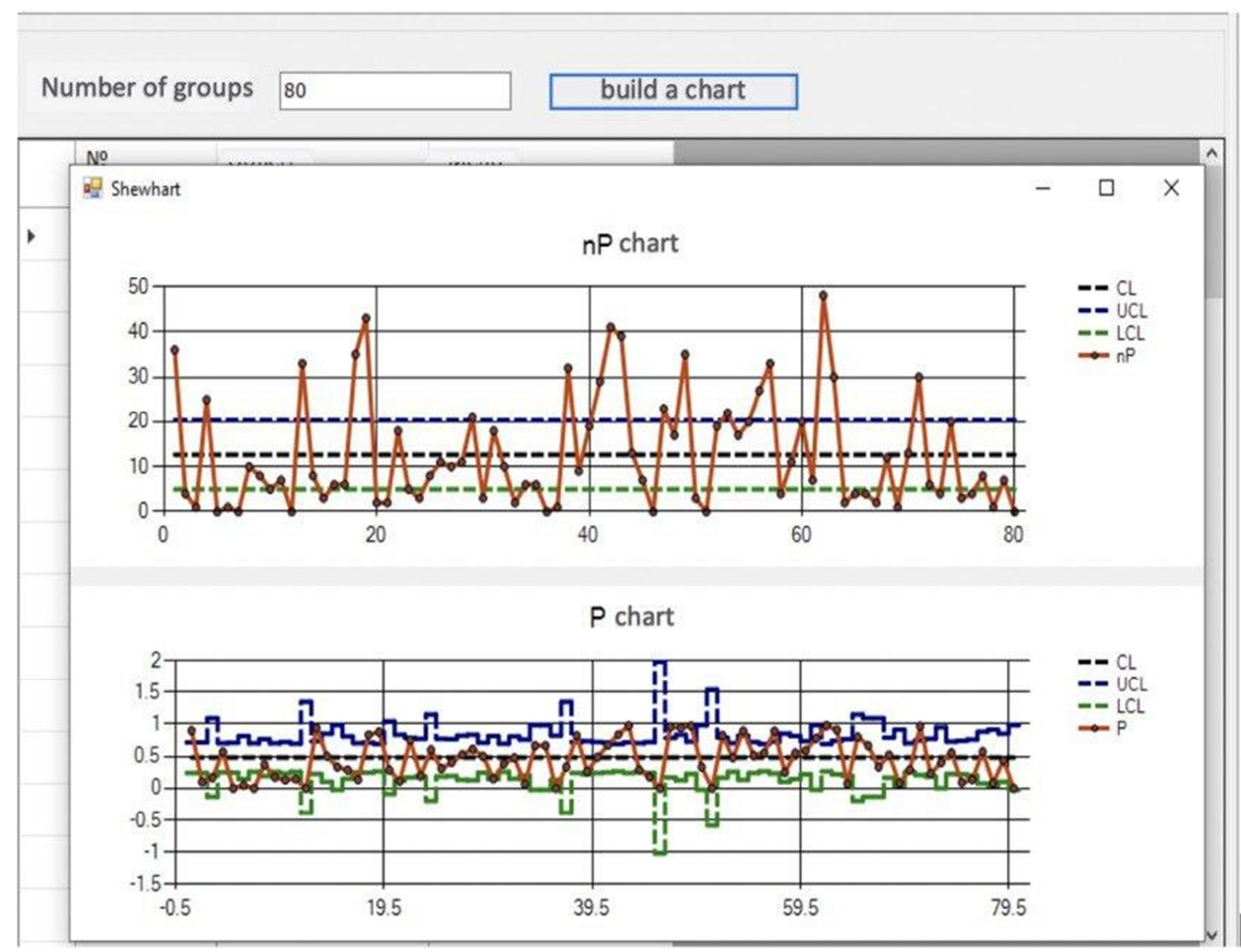

Fig. 5. The overview of the quality tool "Control charts $\mathrm{P}$ and $\mathrm{nP}$ of the number and share of discrepancies" in the developed software.

Table 5. The overview of the quality tool "Control charts $\mathrm{P}$ and $\mathrm{nP}$ of the number and share of discrepancies" in the developed software.

\begin{tabular}{|c|}
\hline Pareto Chart \\
\hline Scatter chart \\
\hline Shewhart X and R control charts \\
\hline Control charts of the number of discrepancies \\
\hline Control charts of the number and share of discrepancies \\
\hline Ishikawa chart \\
\hline Number of subgroups \\
\hline Build a chart \\
\hline Volume \\
\hline Number \\
\hline nP chart \\
\hline P chart \\
\hline
\end{tabular}

One of the available quality tools for statistical analysis of input data in the developed information system is "Control charts of the number of discrepancies $\mathrm{C}$ and U".

The control c-chart is similar to the control $\mathrm{nP}$-chart in the sense that it requires the same sample size for each data point. But instead of building the data ratio in a certain category, as the control nP-chart does, the control c-chart displays counting data, for example, the number of errors. As with other control charts, special cause tests check for emissions and technological shifts. 
The control u-chart is a more general version of the c-chart, used when data points are not taken from samples of the same size. For example, if all loan applications are viewed every week, and the number of applications sent varies on a weekly basis, you can still count errors and display the number of errors by week over time. Due to differences in sample sizes, the control limits will not be constant for each data point. Thus, although the same special reason tests are used as for the other diagrams, the outlier test specifically checks to see if a given data point is outside its own control limits.

The overview of the quality tool "Control charts of the number of discrepancies $\mathrm{C}$ and U" in the developed information system is shown in the figure 6.

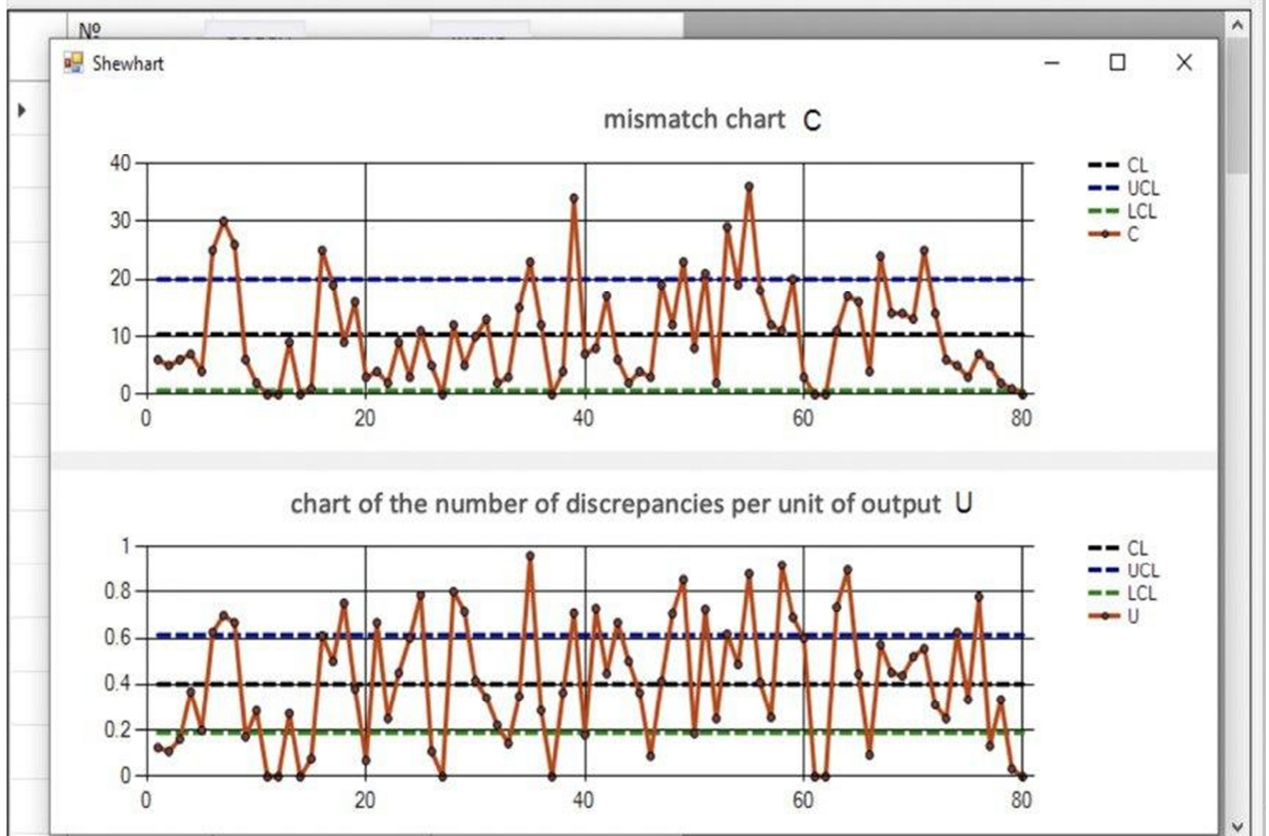

Fig. 6. The overview of the quality tool "Control charts of the number of discrepancies C and U" in the developed software.

Table 6. The overview of the quality tool "Control charts of the number of discrepancies C and U" in the developed software.

\begin{tabular}{|c|}
\hline Pareto Chart \\
\hline Scatter chart \\
\hline Shewhart X and R control charts \\
\hline Control charts of the number of discrepancies \\
\hline Control charts of the number and share of discrepancies \\
\hline Ishikawa chart \\
\hline Number of subgroups \\
\hline Build a chart \\
\hline Volume \\
\hline Number \\
\hline Chart of the number of discrepancies per unit of production U \\
\hline
\end{tabular}


And also there is a tool for planning, monitoring and improving technological processes of production through the establishment of causal relationships in the developed information system - "Ishikawa Chart".

The Ishikawa chart is a very useful tool, because it gives a clear idea of what is causing the problem or phenomenon, what factors have a strong/weak influence on this problem/phenomenon and how to resolve the situation. Ishikawa has the appearance of fish bones and helps a person to "see" causes and effects in certain respects [12].

The overview of this tool in the developed software is shown in the figure 7.

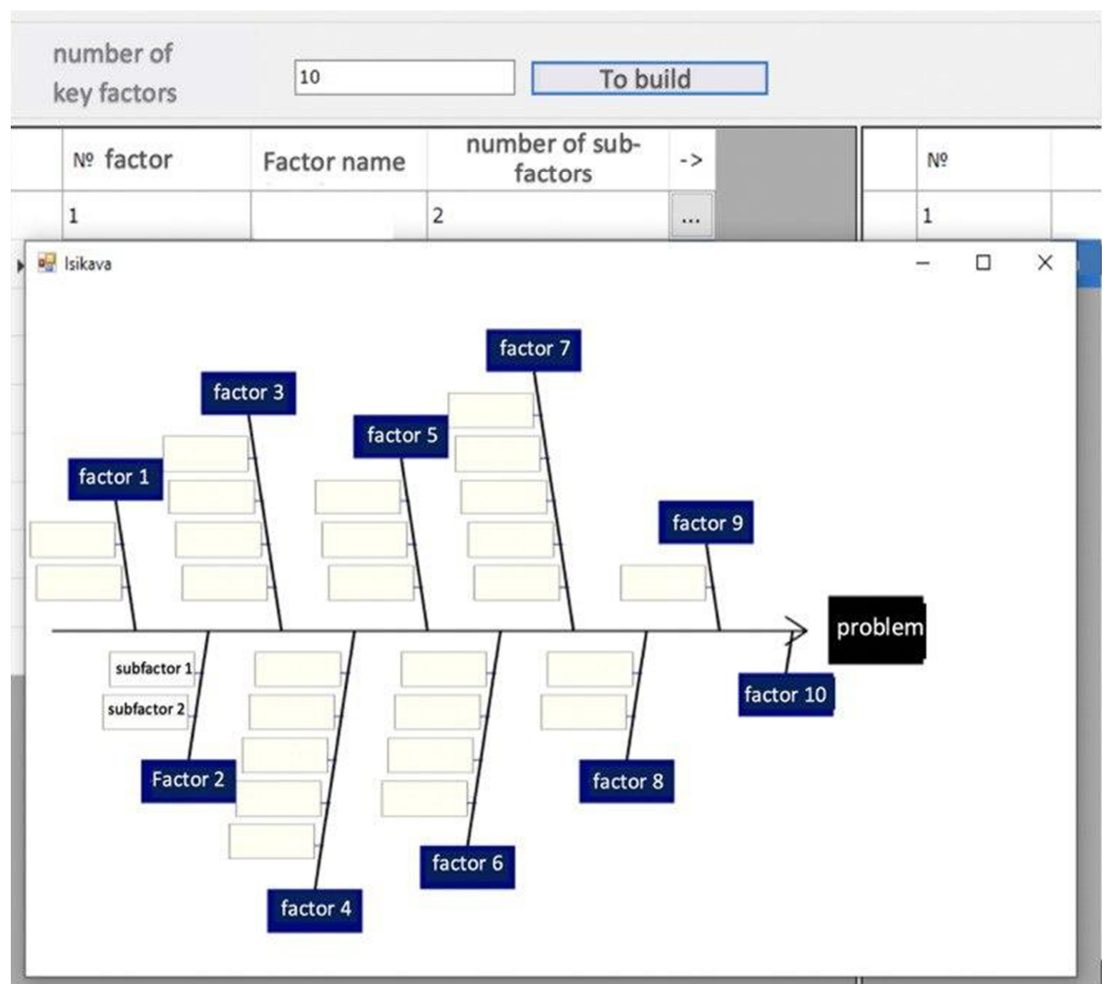

Fig. 7. Overview of "Ishikawa Chart" quality tool in the developed software.

Table 7. Overview of "Ishikawa Chart" quality tool in the developed software.

\begin{tabular}{|c|}
\hline Pareto Chart \\
\hline Scatter chart \\
\hline Shewhart X and R control charts \\
\hline Control charts of the number of discrepancies \\
\hline Control charts of the number and share of discrepancies \\
\hline Ishikawa chart \\
\hline Number of main factors \\
\hline Build \\
\hline Factor number \\
\hline Factor name \\
\hline Number of subfactors \\
\hline Factor 1 \\
\hline Factor 2 \\
\hline Factor 3 \\
\hline
\end{tabular}




\begin{tabular}{|l|}
\hline Factor 4 \\
\hline Factor 5 \\
\hline Factor 6 \\
\hline Factor 7 \\
\hline Factor 8 \\
\hline Factor 9 \\
\hline Factor 10 \\
\hline Problem \\
\hline
\end{tabular}

\section{Discussion and Conclusions}

Due to its flexible and rich functionality, the developed software can be implemented at almost any enterprise engaged in the production of finished products. The target consumers for this information system is planned to choose mainly the agricultural industry, in particular enterprises engaged in the manufacture of agricultural machinery.

Having implemented this system in its production, an enterprise will be able to reduce its production costs by using statistical analysis of the input data and the visibility of the output, which together will increase production capacity [13-15].

\section{Reference}

1. K. Linz, G. Muller-Stievens, A. Zimmerman, Radical change in Business Model, Adaptation and survival in a competitive environment (Alpina Publisher, 2019)

2. K.V. Rochev, Information Technology. Analysis and Design of Information Systems (2019)

3. O.L. Golitsina, I.I. Popov, N.V. Maksimov, Information Systems and Technologies. Tutorial (2019)

4. D.Y. Katalevskiy, A.Y. Ivanov, Modern Agrotechnologies, Economic and Legal and Regular Aspects (2018)

5. A.G. Skhirtladze, Technological Process Automation (2016)

6. I.F. Borodin, Automation of Technological Processes and Automatic Control Systems (2018)

7. L. A. Ginis, Statistical Methods of Quality Control and Management, Applied Software (2019)

8. H. Schildt, Java: A Beginner's Guide (2014)

9. A.K. Ershov, Quality Management (2017)

10. S.I. Solonin, Control Charts Methods (2014)

11. I.V. Maruseva, Modern Management, Classic and Applied Aspects (2018)

12. V.N. Kraev, Management Decision Making Methods (2014)

13. J.C. Choi, C. Kim, J. Mater. Process Technol., 110 (2013)

14. G. Colombo, D. Ferretti, U. Cugini, Proceedings of international symposium on advanced geometric modelling for engineering applications, 2-15 (2014)

15. G. La Rocca, L. Krakers, M.J.L. van Tooren, Proceedings 9th symposium on multidisciplinary analysis and optimization, 2-13 (2014) 